\title{
Moving Universities: A Case Study on the Use of Unconferencing for Facilitating Sustainability Learning in a Swiss University
}

\section{Patricia Wolf $^{1, *}$, Peter Troxler ${ }^{2}$ and Ralf Hansmann ${ }^{3}$}

1 Department of Management, Technology, and Economics (D-MTEC), Center for Organizational and Occupational Sciences, Kreuzplatz 5, 8032 Zürich, Switzerland

2 unbla.org, Hügelstrasse 40, CH-8002 Zürich, Switzerland; E-Mail: peter@ unbla.org

3 Natural and Social Science Interface (NSSI), Department of Environmental Sciences, ETH Zurich, Sonneggstrasse 33, ETH SOL F.7, CH-8092, Zurich, Switzerland; E-Mail: hansmann @env.ethz.ch

* Author to whom correspondence should be addressed; E-Mail: pawolf@ethz.ch;

Tel.: +41-44-632-8194; Fax: +41-44-632-1186.

Received: 29 March 2011; in revised form: 30 May 2011 / Accepted: 14 June 2011 /

Published: 17 June 2011

\begin{abstract}
Unconferencing is a method for organizing social learning which could be suitable to trigger sustainability learning processes. An unconference is defined as participant-driven meeting that tries to avoid one or more aspects of a conventional conference, such as top-down organization, one-way communication and power-relationships based on titles, formal hierarchies and status. This paper presents a case study on the application of unconferencing in a large Swiss university (ETH Zurich) where an unconference was conducted to engage students, academics, staff and external experts in a mutual learning process aimed at the development of project ideas for reducing its $\mathrm{CO}_{2}$ emissions. The study analyzes how the unconferencing format initiated and promoted sustainability oriented group processes during the unconference, and in how far the projects which were developed contributed to a reduction of the university's $\mathrm{CO}_{2}$ emissions.
\end{abstract}

Keywords: unconferencing; group processes; mutual learning; organizational learning; sustainability learning; sustainable university; $\mathrm{CO}_{2}$ emissions; $\mathrm{CO}_{2}$ reduction; sustainable development 


\section{Promoting Sustainability in Higher Education and Society}

There is broad consensus that education must be a driving force for making progress toward sustainable development: "Education, including formal education, public awareness and training, should be recognized as a process by which human beings and societies can reach their fullest potential. Education is critical for promoting sustainable development and improving the capacity of the people to address environment and development issues." [1]. Acknowledging that education is an indispensable element for achieving sustainable development [2], the UN declared the period from 2005 to 2014 as the Decade of Education for Sustainable Development aiming to provide an "opportunity for progressing towards implementing universal quality education that fosters the knowledge, skills, perspectives, and values that lead to a more sustainable future" [3]. Given the large importance of the education sector for sustainable development, the role of universities as leading education and research institutions must be regarded as particularly crucial. Universities can play a pivotal role for societal transformations towards sustainable development and $\mathrm{CO}_{2}$ reduction [4]. Their particular role within society provides them with autonomy, reflexivity and openness, aspects needed to explore innovative paths towards sustainability [5,6]. Universities - themselves heavy producers of $\mathrm{CO}_{2}$ (e.g., mobility of students and staff, heating of rooms, electricity use, paper consumption) — have the potential to promote sustainability and facilitate corresponding learning processes in their own other organizations as well as in other organizations and domains of society through a sustainability oriented transformation of

(i) their internal processes and campus operations,

(ii) community service and outreach,

(iii) research activities,

(iv) the education they provide.

As well as through developing outside relationships, networks and partnerships addressing these four areas [7-13]. The sustainability oriented transformation of a university happens in a stepwise process, but nevertheless, an all-encompassing approach towards transformation which allows addressing these interrelated areas holistically seems most promising. Various studies on the pro-sustainability transformation of universities, point to the importance of a "whole-of-university approach" [5,14,15] which allows for synergetic interlinking of curriculum, research, and pro-sustainability transformation of campus operations. Such a holistic approach corresponds to the concept of sustainable universities $[13,16]$ and implies that for being able to contribute to societal change, universities have to become more sustainable themselves. Improving the sustainability of internal processes, for example by reducing power consumption, paper use, and car and airplane traffic of university members, accordingly represents the most basic aspect of the concept of sustainable universities. Corresponding projects stimulate organizational learning and let a university serve as an authentic role model and partner for other institutions [12,16-18]. The organizational learning processes triggered through such projects can involve more environmentally and socially conscious behavioral decision making and behaviors of individual university members, as well as changes of institutional and structural characteristics and technological, educational, research and management practices and goals. 


\subsection{Designing Events for Initiating Transformations towards Sustainable Universities}

For achieving a maximum transformative momentum towards more sustainable universities, support is needed both top-down from the university board and faculty and bottom-up from students and employees [5,6,19]. This in turn calls for a transformation process fostering the formation of interdisciplinary and cross-boundary teams which would drive the transformation process. An important research question is therefore how group processes can be organized to maximize cooperation, creativity, active participation, mutual trust and learning, and facilitate sustainable collective processes and decisions. However, so far, despite a large number of conceptual papers, research has produced limited empirical insights on how this can be optimally achieved. This study investigates, on an empirical basis, how unconferencing [20,21] was applied in a Swiss university to organize group processes aiming to generate ideas for a pro-sustainability transformation of the university.

Unconferencing is a rather new method for organizing social learning and facilitating creativity and information exchange and it is therefore not yet known how suitable this method is to trigger sustainability oriented organizational learning processes. An unconference is defined as participant-driven meeting that tries to avoid aspects of a conventional conference such as top-down organization, one-way communication and power-relationships based on titles, formal hierarchies and status. Management or facilitation of an unconference is hence primarily concerned with establishing and maintaining an environment supportive to meaningful transactions between participants rather than controlling contributions according to established pecking orders.

The theoretical background and rationale of the method will be explained in the next section. Thereafter, the importance of involvement and participation of all university members, organizational units and levels for achieving pro-sustainable transformations is explained in more detail. The crucial role which mutual learning in transdisciplinary and cross-sectional groups plays is then outlined. Thereafter, the case study on the application of unconferencing in a large Swiss university (ETH Zurich) is presented. Here the unconferencing method was used to engage students, academics, staff and external experts into a mutual learning process [22] aimed at setting up project groups capable and willing to develop and implement proposals for reducing its $\mathrm{CO}_{2}$ emissions. The unconference which was conducted at ETH Zurich is described in detail. Subsequently, how the unconference format and its underlying mechanisms were instrumental in initiating group processes during the unconference will then be analyzed. Thereafter, the project ideas which have been developed in the unconference will be discussed with regard to the numbers of realized projects and the effects of these projects on $\mathrm{CO}_{2}$ emissions. The aim is to show how successfully effects lasted beyond the unconference itself.

\subsection{Theoretical Background of Unconferencing}

Conventional event formats like conferences, expert panels or lectures are less suitable approaches for facilitating organizational learning due to their focus on presentation rather than discussion of content and a tendency to serve political stage setting for preferential topics and the introduction of actors into arenas of power [23]. Transactional event formats like future workshops [24,25], open space technology [26], dialogue conferences [27,28] and unconferences [20,21] represent an alternative. The latter formats are designed for providing participants with a space to meet and for 
enabling them to take over ownership of the event topic. Amongst them, unconferencing seems to provide the best choice for events aimed at initiating a transformation process [21]: Different from open space and future conferences, it uses methods specifically designed to avoid rituals of power, status and hierarchy. Thereby, it allows for the inclusion of structured group processes that prevent negative characteristics of free interaction processes as well as for the involvement of expert knowledge within a participatory process while preventing their dominance over 'conventional' participants. It aspires to engage different members of universities into meaningful dialogues about the future and the transformation that needs to take place for becoming more sustainable. In further development of the methodology applied in dialogue conferences which is focused on facilitating dialogue in group conversations [28], unconferencing additionally makes use of performative methods like performance, video, audio, graphic art, crafting, etc. [29-31].

Epistemologically, unconferencing roots in Luhmann's Social System theory [32], Social Constructionism [33] and the Psychology of Knowledge [34]. Consequently, it supports both systemic and individual processes enabling organizational learning:

1. At system level, unconferences systematically neutralize existing power structures, avoid the build up of new ones and create new structural links through fostering communication between participants from different subsystems. This stimulates negotiating and defining shared significant symbols [34] on the topic and promotes connectivity of communications between university subsystems [32] like departments.

2. At individual level, unconferencing supports perspective taking [34] by stimulating processes of identity development, self reflection and social interaction among conference participants. Knowledge transformation, i.e., the process of "altering current knowledge" [35] is facilitated by reciprocal aspiration of the partners of a communication process to integrate perspectives [36]. Unconferencing helps participants to experience commonly shared interpretation patterns and meanings of topics discussed which contributes to a "we-feeling" based on a commonly shared social reality.

All situational components of unconferences are based on the architectural principles for constructivist learning environments [37]. There are many possibilities to design unconferences corresponding to these principles. The in-depth description of the unconference event at ETH Zurich, which is provided in the method section, shall serve as the prototypical example of unconferencing which is analyzed in this case-study. Still, an exact operational definition of unconferencing based on its theoretical background seems to be missing in previous literature and the concept is therefore highly fuzzy at the present stage, a problem which definitely needs to be tackled in future research.

\subsection{Participation as Key to Transformation}

From the theoretical standpoint, the transformation from a traditional into a sustainable university requires collective agency [38] involving socially coordinated and interdependent efforts for promoting sustainability oriented behavioral, social, technological, and economic changes. Continuous improvement of operations to reduce $\mathrm{CO}_{2}$ emissions and to improve social and economic sustainability indicators critically depends on administrative support and cooperation with academic staff and facility 
management [39]. As stated beforehand, transformative initiatives should thus be supported both top-down as well as bottom-up by students and employees to be effective [5,6,19]. All university members can contribute to sustainable development and $\mathrm{CO}_{2}$ reduction with expertise, knowledge of university operations and creativity. Broad participation in the development of ideas and projects for $\mathrm{CO}_{2}$ reduction also facilitates the acceptance of measures ultimately implemented.

A participative proceeding also provides synergies for the education of the students. Collaboration of students with university administration, professors, external experts, and non-academic staff in mutual learning processes aiming at the pro-sustainability transformation of their own university generates authentic learning opportunities for students, which focus their own life-worlds [40,41]. Later on in their professional life students can transfer the skills gained here to problem-solving processes aiming at sustainability in other contexts, which generates synergies for societal transformation processes towards sustainability in the future.

To sum this up, literature clearly indicates that efforts aimed at university transformations towards sustainability rely upon participation of university members. Therefore, the particular importance of sustainability for organizational survival and the need for an organizational transformation have to be negotiated and agreed in discursive organizational sense making activities amongst the members of the organization $[42,43]$.

\subsection{Transactional Group Processes}

Collaboration between students, university employees, and external experts in mutual learning processes aimed at pro-sustainability transformation of their own university generates authentic learning opportunities for students [40,41]. Several scholars showed that creative group processes like those happening in transdisciplinary case studies in university-based projects strongly support sustainability learning because they facilitate mutual learning processes between different stakeholder groups [8,44-46].

The epistemological roots of the claim that boundary spanning and interactive, bottom up group processes are crucial for an effective transformation of universities towards sustainability emerged from the works of Kurt Lewin [47] and his successors on group dynamics. Their studies indicate a need for learning environments which would stimulate collaborative and innovative thinking, and empower participants to take over responsibility for the transformation process. Lewin [47] demonstrated that involving individuals in structured group discussions with peers can initiate change. According to Werner [48] these transactional approaches involving group-based persuasion integrate social context and thus allow for participants to mutually convince each other that barriers can be overcome and behavior change is in fact feasible [38,49]. Perceived relevance of the messages and message scrutiny could thus be increased for making attitude changes achieved in such discussions more stable and behaviorally effective [50].

In general, events are said to have the potential to act as catalysts or starting points for bringing together members of an organization like a university across organizational boundaries and enable them to contribute to change by building up transdisciplinary teams across university departments that grow and bring forward own ideas [20,22]. 


\subsection{Research Questions}

As described above, so far authors of a large number of conceptual papers agree that events can initiate transdisciplinary, cross-boundary group processes which are crucial for the pro-sustainability transformation of a university. This study investigates on an empirical basis how unconferencing can be applied in a university to organize group processes in a way that cooperation, creativity, active participation, mutual trust and learning are enhanced and sustainability oriented collective processes and transformations are facilitated. Specifically, the research question was if the theoretically predicted effects of unconferencing could be found in its application, particularly in terms of creativity, systems connectivity, mutual learning, and outputs.

It presents a case study of a large Swiss university, ETH Zurich, which used unconferencing as method to engage students, academics, staff and external experts into a mutual learning process [22] aimed at setting up project groups capable and willing to develop and implement proposals for reducing its $\mathrm{CO}_{2}$ emissions. The empirical study first analyses the effectiveness of the unconference conducted through studying the sustainability impacts of the projects which have been developed. It secondly strives for the identification of process factors or mechanisms which account for the instrumentality of the approach in initiating group processes that generate such tangible effects. The main research interest was accordingly to find out whether the unconferencing approach proved suitable to produce pro-sustainability transformations and to investigate which aspects of the unconferencing method enhanced group processes.

\section{Application of Unconferencing for Initiating Pro-Sustainability Transformation at ETH Zurich to Reduce $\mathrm{CO}_{2}$}

ETH Zurich is a large Swiss university: In 2008, it counted 15,093 students, 372 professorships and 9,049 members of scientific staff. Research and teaching is done in the five different disciplines Architecture and Building Science (two departments), Engineering Sciences (six departments), Natural Sciences and Mathematics (four departments), System Oriented Natural Sciences (three departments) and Management and Social Sciences (two departments). In 2008, the university had an annual budget of 1,012 million CHF [51].

Since 1999, the university has a department for the management of environmental resources called RUMBA. The objective of this department is to reduce environmental impact, to ensure efficient energy consumption, and to become a role model in environmental management. Since its establishment, the department has been responsible for the measurement and communication of environmental key data and launched several activities for raising awareness on environmental issues like for example the initiative "bike to work".

In 2008, the university board decided that it would be time for an initiative with higher transformative impact and a more active integration of students into environmental, sustainability oriented activities. It therefore initiated a team called ECOWORKS consisting of representatives of RUMBA, environmental consultants from a university spin off, members of the student association for sustainable development, and a marketing agency. Together, this team was assigned to develop an 
effective initiative for reducing the per capita consumption of 1.5 tons $\mathrm{CO}_{2}$ in 2007 to 1 ton per capita/year with the help of students and staff [52].

The ECOWORKS team developed an online platform where ETH members could hand in, discuss and follow up project proposals for $\mathrm{CO}_{2}$ reduction. The team members however were very clear about the issue that a platform alone would not be sufficient to trigger participation and takeover of responsibility by university members. They therefore decided to have a launch event for the platform for generating implementable project ideas that would lead to a reduction of $\mathrm{CO}_{2}$. They came across a local unconferencing association called "unBla" [20] and decided to apply unconferencing as event format for their launch event.

In November 2008, the university ran a 24-hour unconference with approximately 110 interested volunteering students, professors and environmental experts participating. The project proposals developed during the event were evaluated by a jury and after the event by experts of the university responsible for realizing the most viable and promising project ideas. Real impact of the event on sustainability of campus operations was ensured and communicated to the conference attendees beforehand to motivate them for active engagement.

The event was designed as follows:

1. It started at midday with a general introduction by the university's vice president followed by a domain mapping exercise aimed at creating a common understanding of the topic domains future projects would have to address. Already during registration process, participants signed in for one of the five domains (i) sustainability in general, (ii) water, (iii) energy, (iv) mobility and (v) waste. At the event, they were distributed in groups according to their interest and worked out large wall papers highlighting issues in their topic domains as well as links between the domains.

2. The domain mapping was followed by a networking exercise where participants met in a moderated process and talked to at least five other participants who were unknown to them before. This step aimed at giving people an understanding about who the other participants were, at making them feel more comfortable, creating ties between them, breaking up existing groups and connecting people with similar interests and ideas.

3. The next step was an idea market where people first described their ideas shortly on dedicated sheets. They then presented their ideas to the whole audience, thereby identifying people with similar ideas and connecting to them. Idea sheets were then exhibited on the walls and participants were given the opportunity to talk to idea owners and subscribe to ideas to form project teams. During this phase, from 50 initial ideas 17 project teams emerged which have been facilitated to plan their work until the next day.

4. The idea market was followed by a networking reception and a dinner where business people and experts came in and helped the student groups with sharpening their ideas.

5. After dinner, work in project groups started. The proposal format and requirements were introduced to the groups and they started to work out their project proposals. Participants were free to work overnight; however the last work groups stopped at 2 am to have a rest.

6. Business expert breakfast was served between 8 and 10 am on the second day. Here again experts joined the students and helped them to mature their ideas. The project maturation phase 
lasted until midday, as project proposals had to be handed in exactly 24 hours after the event started.

7. While a jury of university professors and $\mathrm{CO}_{2}$ experts from industry evaluated the proposals, students presented their work to each other and acted as a peoples' jury who selected the two most popular project ideas.

8. Two hours later, the jury presented the winning projects in an award ceremony. The event closed with a reception.

\section{Methods}

Our study was aimed at investigating on an empirical basis how the unconference format and its underlying mechanisms were instrumental in organizing group processes in a way that cooperation, creativity, active participation, mutual trust and learning are enhanced and making their effects last beyond the unconference itself. This is an exploratory research question insofar as it calls for identifying and describing the underlying mechanisms of unconferencing that became effective at organizational (university), social (group) and individual level as well as for revealing how these effects contributed to ecologically sustainable outcomes and the transformation of the university. It implies an inductive research design because the phenomenon at hand is as yet poorly understood. Therefore, a case study appeared as particularly appropriate research strategy because by using multiple sources of evidence [53], this research design allows for investigating “(...) a contemporary phenomenon within its real-life context, when the boundaries between the phenomenon and the context are not evident" [54]. We triangulated different qualitative research methods [55,56], namely participatory observation, narrative interviews, a participant survey and document analysis. Method triangulation allowed us to gather complementary data on the issue.

\subsection{Participatory Observation}

Seven researchers participated in the event in the role of observers-as-participants [57,58]. Conference participants were informed that there were researchers observing their actions and communications, but the identity of these people remained wholly concealed. The aim behind this ethnographic research approach [59] was to shed more light on revealing group effects, i.e., how social order in unconferences is (self-) generated in and through its practices [60]. The research field emerged at the moment we started the observations and dissolved 24 hours later with the end of the unconference; the short time frame however made it difficult for researchers to gather meaningful data besides their engagement within the groups they observed.

We therefore followed the advice by Flick [61] and used a structured observation guideline for documentation. The researchers filled it in for the different phases in the overall group of participants (domain mapping, networking, idea market) and five different phases of project work (starting phase after dinner, after the first two hours, after breakfast the next morning, two hours after breakfast, $30 \mathrm{~min}$ before hand in of proposals). They applied different observation guidelines for these phases which represent our operationalization of potential effects of power, the creation of structural links, individual knowledge transformation and social learning during the event into observable individual 
and social actions. They additionally contained a field labeled with 'other notes' which allowed for documenting any other observation.

The findings were analyzed in various iterative circles: In the first step, seven student researchers and a professor interpreted (structured observations) and coded (open observations) the material independently. In the next step, students came together in groups of three or four people and developed a group interpretation. Then, the findings of the two groups and the professor were compared and a common interpretation was developed.

\subsection{Narrative Interviews}

In narrative interviews [62], 20 participants were asked to reconstruct their individual experience during the unconference. The narrative interview technique provides access to experiences that constitute the everyday reality of the narrators through asking respondents to tell stories without offering any elaborated categories or concepts [63]. By emphasizing and repeating specific aspects and interpreting certain occurrences, the narrator's frame of reference becomes accessible.

The narrative interviews were held right after groups handed in their proposals. The interviewees have been asked the following question to stimulate the narration: "Mister/Miss..., I would like to ask you to tell me what happened to you during the last 24 hours. Please start with the situation at the beginning of the event and describe thereafter everything that happened during the event until now."

To analyze the interviews, four student researchers and a professor coded the material independently; they noted themes and clustered them into topics [64]. To reduce the influence of their own recognition patterns and increasing the interpretive validity, student researchers then came together and developed a common group interpretation. This interpretation was compared to the interpretation of the professor in a final step.

\subsection{Participant Survey}

At the end of the unconference, participants were asked to fill in a participant survey [64]. The survey contained four qualitative questions which asked what the participants learned during the event, what their major benefit was, what they would suggest to change in the organization/design of the event and how they felt right after the event. The participant survey was handed in by $48(43 \%)$ of the 112 participants.

The answers to the qualitative questions were analyzed in the same sequence as the observations. Again, an open coding procedure was applied [64] as described above for the narrative interviews.

\subsection{Document Analysis}

Documents "represent a specific version of realities constructed for specific purposes." [61,65]. In order to understand how the institution assessed and communicated the effects of the unconference as well as their sustainability, we collected documents that were produced between November 2008 and April 2010 by different university actors involved in the unconference and the transformation process such as jury members, event organizers and university. The body of documents includes jury 
evaluations, newsletters and environmental reports of the university. These documents were again analyzed with an open coding procedure as described above in the same sequence as the other data.

\section{Findings}

Below, we describe the process factors or mechanisms of unconferencing that were operative in the group work and the mutual learning which took place (Sections 4.1-4.3). These aspects account for the instrumentality of the unconferencing approach in initiating group processes that generate tangible effects in pro-sustainability transformations. We then (Section 4.4) have a look at the effectiveness of the unconference in terms of tangible effects (in particular $\mathrm{CO}_{2}$ reduction) through studying the actual and prospective sustainability impacts of the projects which have been developed.

\subsection{Open Atmosphere and Creativity}

An important topic in the narrative interviews was the atmosphere that was described as open, creative and supporting idea sharing, or, as one participant puts it: "I perceive it as a really cool open source atmosphere". People liked the large room without tables and chairs for the interactive sessions, and they enjoyed the decoration. They also felt esteemed by the organizers and the service personnel, apparently an unusual experience for students which has been highlighted several times. Participants also liked the good humor within the group.

When telling what happened to them during the last 24 hours, interviewees talked in narrative interviews about the first phase of the event until the end of project team formation at step 4 much more than about the proposal development phase in teams. It seems as if they collectively divided the event into two phases: the creative, interactive and easy phase in the big group with all participants, and the serious and hard working phase in the project groups. While everybody talked a lot about the first phase and half of the interviewees even remembered in detail all sub-activities of bigger tasks (domain mapping, networking, idea market) — except the opening speech (!)) — the work in the project teams was only briefly described. We assume that this is caused by the first part being unusual to them, while they are used to project work which is a standard work process in their university studies.

\subsection{Systems Connectivity in a Power Free Environment}

The list of participants reveals that the event attracted participants from 13 different disciplinary backgrounds, i.e., agricultural and food sciences, architecture, construction and geomatics, bio systems, chemistry and applied biosciences, earth sciences, informatics, information and electro technology, material sciences, mechanical and process engineering, management and ecosystems, and physics. We also recognize diversity when we look at the educational backgrounds of the participants: The event attracted Bachelor, Master and postgraduate students as well as $\mathrm{PhD}$ students and associate professors.

The observers documented their experiences with the creation of structural links and power relations. During the whole event, they did not observe a single exclusion of participants due to first level classifications (the clothes, the experience, the voice, etc. of others). Observations show that existing group structures have been systematically broken up during the first phase of the event, that a lot of communication took place between people from different disciplines and that new groups 
emerged during the idea market. Figure 1 below visualizes how the dissolution of existing groups and the creation of new ones happened accordingly to the sequence of process steps from domain mapping (first exercise) via networking (second exercise to idea market (third exercise).

Figure 1. Dissolution of existing, and emergence of new, groups over time.

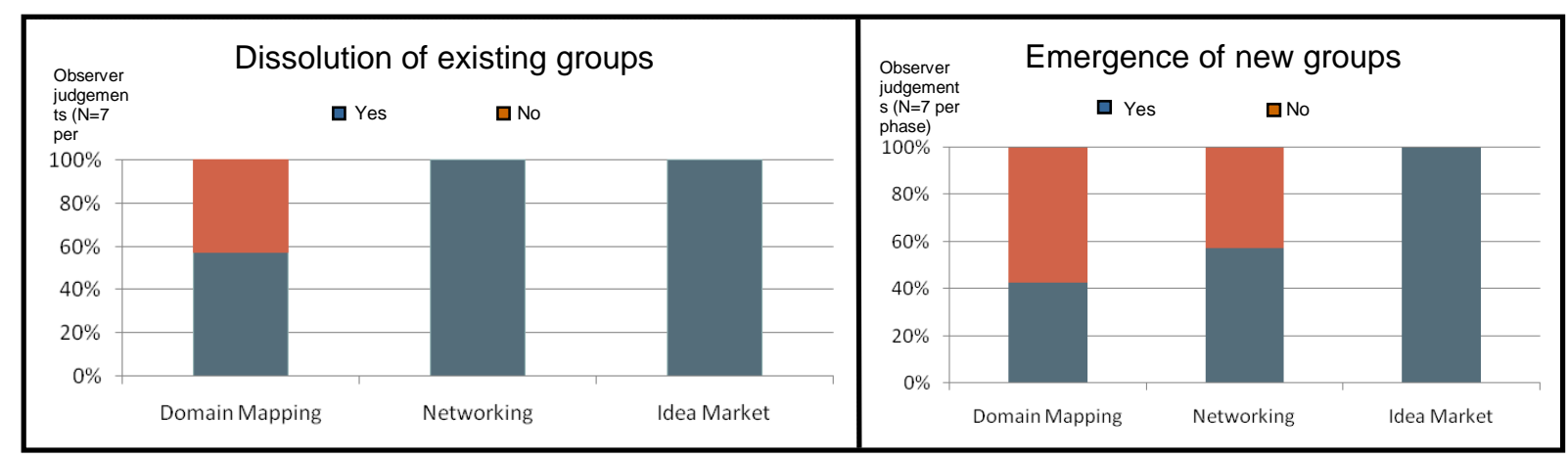

Findings from the survey and the narrative interviews support these observation results. In their qualitative answers to the survey, participants highlighted that they benefitted most from meeting other people through the networking exercise (28 answers). In narrative interviews, the networking exercise has been praised by most interviewees for supporting them in getting to know other people from other departments and disciplines, engaging into intensive dialogue with them, identifying participants with similar issues and ideas and developing a feeling of group belonging.

This creation of structural links happened in a power free environment, i.e., an environment that is not determined by pre-existing power structures such as hierarchies or professional status. We found in the narrative interviews that cooperation happened between participants with similar ideas and that a common vision of the project idea emerged from intensive discussions. Findings from the observations additionally show that during the work in the project groups, roles in the groups emerged due to the expertise of people instead of a professional status (like Dr., Prof. etc.) and task assignment happened rather by volunteering than by orders. In project teams, participants actively listened to each other and presented even unfinished ideas. Misunderstandings were regularly perceived as such and discussed; criticism was formulated in an objective manner.

\subsection{Mutual Learning}

With our case study, we investigated whether unconferencing supported perspective taking, creativity, knowledge exchange, synthesis and transformation of knowledge, and if so, how.

From our data, we found that social learning and knowledge transformation are closely related. In their answers to the qualitative questions of the survey participants stated they enjoyed working on own ideas and bringing them forward ( 8 answers) as well as experiencing a large group moderation process (16 answers). They furthermore acknowledged that their major learning gains resulted from capitalizing on other peoples' expertise what enabled them to generate new ideas in the thematic area of $\mathrm{CO}_{2}$ reduction (20 answers). Additionally, they confirmed an increase of their capabilities for working effectively in a team (19 answers). 


\subsubsection{Facilitation}

A lot of positive aspects of facilitation have been mentioned in the narrative interviews especially concerning the first phase of the event in the large group. One motivation to participate in the event mentioned by half of the interviewees was curiosity concerning the event format. As they never participated in an unconference before, they had no clear idea about what would happen and how the event would be designed in detail. When reconstructing their experiences, interviewees highlighted that facilitators excellently structured the event and guided the open innovation process. Or, as one of the participants puts it: "It is one of the best workshops I ever attended because you know, everything went so in order" (sic! for smoothly Ed.). Participants underlined that facilitation enabled them to exchange ideas, to make points of view explicit, to bring in their own ideas and to develop them further. One third of the interviewees reported learning effects related to the positive impact of the different methods applied during the unconference on the event results because these methods fostered the formation of motivated and competent project teams and in consequence the development of high quality proposals.

\subsubsection{Motivation and Engagement}

The major motivation to engage in the event mentioned by the majority of the interviewees was to impact the way the university deals with $\mathrm{CO}_{2}$. They strived for developing and implementing own ideas. This is also reflected in the strong orientation towards developing projects as well as master and $\mathrm{PhD}$ theses out of the work done at the event. The interviews showed that most participants did not just come for a two day event but aimed at making their project happen afterwards. The willingness to engage in event activities clearly impacted what participants reflected upon and were able to learn, in other words to how far individual knowledge transformation took place. Those who aimed at implementing their own ideas described the process of convincing other people to join their team as intensive and sometimes even exhausting. About one third, i.e., seven of the interviewees reflected their role as idea owner and reported learning points about own competences (like being precise, providing good arguments, leading group discussions, etc.). Reflection has been indicated as important trigger for changing own behavior. For example, participants who did not indicate clear preferences and competences felt that finding interesting communication partners during the networking exercise was difficult. Several interviewees report that they reflected upon the issue and changed their behavior for the following idea market phase: Here, it was important to them to formulate ideas and how they could contribute to them in a very clear manner.

\subsubsection{Engagement and Sensing Time}

The amount of active participation also strongly impacted on how time was sensed by the participants. Almost half of the interviewees mentioned that although the first interactive phase lasted four hours, they totally lost track of time. Another third valued the first part of the event a lot but always felt that they should start working now: These participants usually arrived at the event with a strong vision of an idea and some followers to form a team and were very keen to work on the idea. 
Two interviewees who reported that they did not engage actively in several tasks felt that these tasks took too much time.

\subsubsection{Adaptation of Project Ideas and Roles}

Observation results show that there was not a single project group where participants kept the initial project idea without modification. Instead, participants discussed different opinions and developed a common project vision which was different from the initial idea. This indicates a social learning process involving adaptation of initial individual viewpoints (knowledge transformation). Another effect of social learning mentioned by all participants was the one of developing common project team working routines enabling them to cooperate in the morning better than the previous evening.

During the project proposal development phases, observers identified several changes in the roles of project team members. On average, there was at least one role change per phase in three out of the seven observed project groups. As role changes have been reported as not forced but self-motivated, they indicate knowledge transformation of individuals who redefine their own role in the group.

\subsection{Outputs}

Within the 24 hours of the event, participants developed 17 project proposals which were all eligible for evaluation and entailed realistic ideas for $\mathrm{CO}_{2}$ reduction at the university. The project ideas ranged from the Eco-Paparazzo, an internet portal to pillory energy waste, to construction measures (e.g., implementation of heat exchangers, use of solar- and wind energy) and technical tricks like a better switch-off of the standby modus or a behavior change project called "choose stairs-not lifts" [52]. A list of the proposals with short descriptions is presented in Table 1 below.

Table 1. List of proposals (adapted from [66]).

\begin{tabular}{|l|l|}
\hline \multicolumn{1}{|c|}{ Project title } & \multicolumn{1}{c|}{ Whort description } \\
\hline $\begin{array}{l}\text { Improved Printing } \\
\text { System }\end{array}$ & $\begin{array}{l}\text { Improving ETH's printing system to save a major part of the printing resources like } \\
\text { paper, toner, hardware, power. }\end{array}$ \\
\hline Trainforplane & $\begin{array}{l}\text { Optimizing the current travel behavior of ETH staff by developing new processes for } \\
\text { business-trip booking } \\
\text { Raise awareness of employees concerning } \mathrm{CO}_{2} \text { emissions and real advantages } \\
\text { of plane vs. train. } \\
\text { Eventually change existing rules of reimbursement of travel expenses. }\end{array}$ \\
\hline Eat less $\mathrm{CO}_{2}$ & $\begin{array}{l}\text { Effective reduction of meat consumption in the ETH dining halls by } \\
\text { increasing the appeal of vegetarian meals, } \\
\text { altering meat containing meals. }\end{array}$ \\
\hline $\begin{array}{l}\text { PUBLICA Low } \\
\text { Carbon Fund }\end{array}$ & $\begin{array}{l}\text { Eco-friendly investment of pension funds with the potential to compensate the } \\
\text { indirect } \mathrm{CO}_{2} \text { footprint of the institution about four times. }\end{array}$ \\
\hline
\end{tabular}


Table 1. Cont.

\begin{tabular}{|c|c|}
\hline Project title & Short description \\
\hline \multicolumn{2}{|r|}{ Further proposals } \\
\hline Energy Paparazzi & $\begin{array}{l}\text { Daily updated yellow-press style website where individuals who commit } \\
\text { environmental sins are exposed. }\end{array}$ \\
\hline ecoAct & $\begin{array}{l}\text { Raise awareness of students on their personal } \mathrm{CO}_{2} \text {-impact and possibilities to reduce } \\
\text { it through signs across the campus and a } \mathrm{CO}_{2} \text { information pool (website). }\end{array}$ \\
\hline Water-heat-exchange & Implementing heat-exchangers in wastewater pipes \\
\hline Akanthus & Real-time life cycle assessment \\
\hline Choose Stairs-not lift & Raise awareness about negative environmental impacts of using lifts instead of stairs \\
\hline Inno-Rain & Using rainwater for toilet flush \\
\hline [re]CYCLING & Producing energy by sportive activities on workout equipment in the gym at ETH. \\
\hline $\begin{array}{l}\text { Windows lab } \\
\text { overnight shutdown }\end{array}$ & $\begin{array}{l}\text { Adapting an existing solution from the ETH main building to another building to shut } \\
\text { down overnight student PCs and lab computers. }\end{array}$ \\
\hline Human dynamo & $\begin{array}{l}\text { Transforming energy resulting from stepping on the floor into electric power by } \\
\text { dynamos }\end{array}$ \\
\hline ENValuate & $\begin{array}{l}\text { Web-based tool for monitoring and assessing alternative options of all aspects of } \\
\text { ETH which have an effect on the environment. }\end{array}$ \\
\hline $\begin{array}{l}\text { Figure of your } \\
\text { lifestyle }\end{array}$ & $\begin{array}{l}\text { Calculator for assessing individual } \mathrm{CO}_{2} \text { consumption which also provides easy } \\
\text { options for reductions. }\end{array}$ \\
\hline SunWindProject & Installing a solar and wind energy park at the roof of a large department building \\
\hline $\begin{array}{l}\text { Integrated Energy } \\
\text { Production }\end{array}$ & $\begin{array}{l}\text { ETH will produce and convert energy fully based on renewable and } \mathrm{CO}_{2} \text {-free } \\
\text { technologies. }\end{array}$ \\
\hline
\end{tabular}

Experts from the jury acknowledged that the number and quality of ideas was extraordinary high [52] which suggests that unconferencing is a viable method for developing high quality project proposals in a relatively short period of time. In the narrative interviews, several interviewees talked about enthusiasm in their group to implement the proposal developed and high interest in the (upcoming) decision of the jury. One of them pointed to the need for investment by the university for implementing the ideas. Most interviewees express pride in the results of their work. Similarly in the participant survey, 11 participants affirmed their motivation to continue to work on their project after the event (without having been asked about this motivation).

\subsection{Project Implementation and Sustainability}

Of the 17 project proposals, 10 projects have been realized. Not all projects are equally well documented, so it is a matter of guesswork to quantify their ecological impact.

Two projects actually aimed to reduce current $\mathrm{CO}_{2}$ emissions and energy consumption. The Windows Lab Overnight Shutdown project developed and implemented a system to switch of windows machines in computer labs at night. The project was trialed in a department with a total of eight computers. Shutting down the machines over night saved about $30 \mathrm{kWh}$ per day-double the amount on weekends [67]. Using ball park figures (143 $\mathrm{g} \mathrm{CO}_{2} / \mathrm{kWh}$ electricity, 'Swiss mix'; compare http://www.co2-monitor.ch/en/facts/glossary/) that is about 2 tons of $\mathrm{CO}_{2}$ per year. The pilot Eaternity (Eat less $\mathrm{CO}_{2}$ ) reduced the $\mathrm{CO}_{2}$ emissions of canteen food by reducing the amount of meat used and by 
increasing the proportion of locally sourced ingredients. Students were very successful in doing so, and recently asked to adapt this concept to a canteen of a big company. On the first day of its three-week trial Eaternity served about 300 meals which is one fifth of the average 1,500 meals served daily [68]. In total, the trial was reported to have saved 1.1 tons of $\mathrm{CO}_{2}$ [69].

The two projects that were concerned with recovering energy spent at spinning bikes at the campus gym, the [re]CYCLING Project, and the Human Dynamo project, aiming at recovering the energy of people walking. ASVZ Energy Recovery Project projected an energy production of about 2.51 MWh per year (based on 25 bikes); [70]. Using the above ball park figures that would result in 0.36 tons of $\mathrm{CO}_{2}$ saved. A prototype of an energy generating spinning bike has been built, revised estimates were at $219 \mathrm{kWh}$ per year for one bike or 5.5 MWh per year (0.78 tons of $\mathrm{CO}_{2}$ ). For the Human Dynamo project no actual calculations are available. The team around Rotterdam's "sustainable dancefloor" project showed that the energy generated by one dancer in such system would be "maximum 80-100 W or an average of 20-30 W over a time period of $10 \mathrm{~s}$ " [71]. These figures do not allow a conversion into tons of $\mathrm{CO}_{2}$ since installed floor space and rate of use are driving factors; studies from the use of the system are not available since the "sustainable" dance club in question, depending heavily on city council money, closed down in 2010 after less than two years operation when subsidies were cut.

The two projects ENValuate and ecoAct focused after the event on the $\mathrm{CO}_{2}$ emissions of the campus events and developed proposals to reduce them. They realized two projects, the project Sustainable Conference Organization which analyzed an academic conference, and the project ASVZ Sola-Staffette Oekobilanz which analyzed an annual students' sports event. The academic conference analyzed in the Sustainable Conference Organization project was attended by 356 participants from 32 countries. It generated 475 tons of $\mathrm{CO}_{2}$ (97\% of which from flights alone). Recommendations for future conferences are to avoid, reduce or offset $\mathrm{CO}_{2}$ emissions from travel, to work with "sustainable" hotels and catering and to reduce printing [72]. ASVZ Sola-Staffette Oekobilanz study found that 74\% of total $\mathrm{CO}_{2}$ emissions were caused by travelling to the event, a lower percentage than for the conference since the event is of local nature. Depending on the calculation model, the event caused between 125 (realistic scenario) and 201 ('pessimistic' scenario) tons of $\mathrm{CO}_{2}$ emissions — while a standard calculator would estimate 240 tons of $\mathrm{CO}_{2}$ emissions. The study discusses various options to reduce emissions; however $\mathrm{CO}_{2}$ compensations is seen as the most adequate solution [73].

The four remaining projects dealt with tools for the analysis of buildings or household appliances, and with awareness and change campaigns for education and research. Since these projects did not generate any direct positive effect in terms of $\mathrm{CO}_{2}$ or energy, we exclude them from the further analysis.

\section{Discussion and Conclusions}

From our findings presented above, we can draw the following conclusions concerning our research questions:

The empirical study first aimed at analyzing the effectiveness of the unconference conducted through studying the sustainability impacts of the projects which have been developed. As discussed, the unconference developed within 24 hours 17 high quality project proposals of which 10 were implemented for transforming the university towards lower $\mathrm{CO}_{2}$ emissions. These projects reduced $\mathrm{CO}_{2}$ with the above specified amounts. 
The unconference was a first step the universities' way towards more sustainability. It did not only produce project proposals but also generated motivation amongst the participants to implement these projects [66,74-76]. Our study enabled us to identify some process factors and mechanisms which presumably account for the instrumentality of the approach in initiating group processes that generate such tangible effects. We found that first, in the case study presented unconferencing supported the creation of structural links between participants from different organizational (university) sub systems and led to improved system connectivity. Especially during the first phase, a lot of interdisciplinary contacts were established. Participants developed a feeling of belonging. We also showed that discussions took place in a power free environment, participants engaged in the different processes openly and roles and tasks have been assigned due to expertise instead of status. In the project groups, everybody's voice was esteemed. Second, we found out that participants engaged in a mutual learning process. We identified different processes of perspective taking, knowledge sharing, development of common ideas and individual knowledge transformation based upon self reflection. We also saw that facilitation was important to bring these effects about. Especially the application of performative methods in the first phase of the event enabled participants to open up and develop and share ideas. The individual engagement impacted the experiences made and the learning outcomes of people. Even participants who did not engage very actively into networking experienced its effects: How one participant puts it, the "networking happened automatically, people came and talked to me". However, it seems as if active participation stimulated reflection, and especially idea owners who organized a project team for their idea talked a lot about their learning gains during the process. Individual knowledge transformation was always strongly linked to social learning processes, an effect which we found especially in phases where ideas have been developed, merged and negotiated in the project teams.

In summary, our findings suggest that unconferencing is a promising format for facilitating the initiation of a pro-sustainability transformation of a large university. They show that unconferencing actually achieved systems connectivity, enabled mutual learning and probably outperformed more traditional formats in terms of output on this occasion. It is certainly plausible that the basic aspects and methodology of unconferencing are not confined to the topical domain and type of organization that were addressed in this case study. Certainly, unconferencing can equally be used for enhancing other organizational learning processes that critically depend on systems connectivity and mutual learning.

Yet further research is needed, particularly on a meta-level, to trace the effects of unconferencing across universities but also a range of other domains and organizations. Likewise, the influence of unconferencing as a method as compared to the actual skills of the facilitating teams would need to be investigated. Finally, the question needs to be addressed under which circumstances unconferencing might or indeed might not be the most promising approach to achieve transformation goals, as compared to more traditional methods of facilitating transformation and societal and/or cultural change. Participative starting events are only one part of the pro-sustainability transformation of universities. The embedding of such events in the overall transformation process as well as the optimal event design are practice oriented research foci for which the present study contributed empirical data, but where many aspects are still needed to be investigated. The present research indicates that unconferences have some advantages for generating transformative motivations, developing team spirit, and generating cross sectional and hierarchical communication and linkages as compared to conventional event formats which predominantly consist of front lectures or presentations, and which leave room for 
networking mostly only in breaks, poster sessions or conference dinners, accompanying cultural events and outings. In relation to optimal design of unconferencing, a prototypical unconference arranged in temporal order of eight steps starting with general introduction, domain mapping and networking exercise, and idea market on day 1 and finishing with an award ceremony on day 2 has been described and the positive effects achieved by applying this event designed could be analyzed and demonstrated empirically. Still various possibilities of designing unconferencing events and organizing and realizing the constituent parts exist, yet there is little empirical knowledge on the effects of such variations.

\section{Acknowledgements}

The authors thank Alfred Posch, Roman Seidl, Kip Jones, Irene Lopez de Vallejo and Elke Schüssler and Fridolin Brand for valuable comments on a previous version of this manuscript. The authors are in addition indebted to Ed Mitchell and Abdul Samad (Sami) Kazi who helped to develop the concept presented above as well as the participants, organizers and initiators of the 2008 Ecoworks 24 Hours Creative Conference at ETH Zurich, especially Dominik Brem (ETH Zurich), Martin Raeber and Marc Vogt, for their consent to study the event and to publish the results. The authors also wish to acknowledge their gratitude and appreciation to all members of the student groups from Lucerne University of Applied Sciences and Arts-Business who were involved in this study for their contributions; without their support, this study would not have been possible.

\section{Author Note}

Preliminary findings on the processes triggered by the unconference described in this article have been reported in Wolf, P., Hansmann, R., and Troxler, P. (2011). Unconferencing as method to initiate organisational change: A case study on reducing $\mathrm{CO}_{2}$ emissions of a university. Journal of Organizational Change Management, 24(1), 112-142.

\section{References}

1. United Nations Conference on Environment and Development (UNCED). Agenda 21: Earth Summit-The United Nations Programme of Action from Rio de Janeiro; United Nations: New York, NY, USA, 1992.

2. UNESCO. Education for Sustainability, from Rio to Johannesburg: Lessons Learnt from a Decade of Commitment; UNESCO: Paris, France, 2002.

3. UNESCO. Contributing to a More Sustainable Future: Quality Education, Life Skills, and Education for Sustainable Development; UNESCO: Paris, France, 2005.

4. Martens, P.; Roorda, N.; Cörvers, R. Sustainability, Science, and Higher Education: The Need for New Paradigms. Sustainability 2010, 3, 294-303.

5. Adomssent, M.; Godemann, J.; Michelsen, G. Transferability of approaches to sustainable development at universities as a challenge. Int. J. Sustain. Higher Educ. 2007, 8, 385-402.

6. Gudz, N.A. Implementing the sustainable development policy at the University of British Columbia: An analysis of the implications for organisational learning. Int. J. Sustain. Higher Educ. 2004, 5, 156-168. 
7. Hansen, J.A.; Lehmann, M. Agents of change: Universities as development hubs. J. Clean. Prod. 2006, 14, 820-829.

8. Hansmann, R. Linking the components of a university program to the qualification profile of graduates: The case of a sustainability-oriented Environmental Science curriculum. J. Res. Sci. Teach. 2009, 46, 537-569.

9. Hansmann, R. "Sustainability learning": An introduction to the concept and its motivational aspects. Sustainability 2010, 2, 2873-2897.

10. Lidgren, A.; Rodhe, H.; Huisingh, D. A systemic approach to incorporate sustainability into university courses and curricula. J. Clean. Prod. 2006, 14, 797-809.

11. Lozano, R. Incorporation and institutionalization of SD into universities: Breaking through barriers to change. J. Clean. Prod. 2006, 14, 787-796.

12. Stephens, J.C.; Hernandez, M.E.; Román, M.; Graham, A.C.; Scholz, R.W. Higher education as a change agent for sustainability in different cultures and contexts. Int. J. Sustain. Higher Educ. 2008, 9, 317-338.

13. Velazquez, L.; Munguia, N.; Platt, A.; Taddei, J. Sustainable university: What can be the matter? J. Clean. Prod. 2006, 14, 810-819.

14. McMillin, J.; Dyball, R. Developing a whole-of-university approach to educating for sustainability. Linking curriculum, research and sustainable campus operations. J. Educ. Sustain. Dev. 2009, 3, 55-64.

15. Selby, D. Towards the sustainability university. J. Educ. Sustain. Dev. 2009, 3, 103-106.

16. Beringer, A. The Lüneburg sustainable university project in international comparison: An assessment against North American peers. Int. J. Sustain. Higher Educ. 2007, 8, 446-461.

17. Albrecht, P.; Burandt, S.; Schaltegger, S. Do sustainability projects stimulate organizational learning in universities? Int. J. Sustain. Higher Educ. 2007, 8, 403-415.

18. Marcell, K.; Agyeman, J.; Rappaport, A. Cooling the campus: Experiences from a pilot study to reduce electricity use at Tufts University, USA, using social marketing methods. Int. J. Sustain. Higher Educ. 2004, 5, 169-189.

19. Koester, R.J.; Eflin, J.; Vann, J. Greening of the campus: A whole-systems approach. J. Clean. Prod. 2006, 14, 769-779.

20. Wolf, P.; Troxler, P. The Proof of the Pudding is in the eating - But what was the Pudding in the First Place? A proven unconferencing approach in search of its theoretical foundations. Qual. Soc. Res. 2008, 9, Art. 41. Available online: http://www.qualitative-research.net/index.php/fqs/ article/view/415/900 (accessed on 28 May 2009).

21. Wolf, P.; Hansmann, R.; Troxler, P. Unconferencing as method to initiate organisational change: A case study on reducing $\mathrm{CO}_{2}$ emissions of a university. J. Organ. Change Manage. 2011, 24, 112-142.

22. Scholz, R.W. Mutual learning as a basic principle of transdisciplinarity. In Transdisciplinarity: Joint Problem-Solving Among Science, Technology and Society. Workbook II: Mutual Learning Sessions; Häberli, R., Scholz, R.W., Bill, A., Welti, M., Eds.; Haffmans: Zurich, Switzerland, 2000; pp. 13-17. 
23. Anand, N.; Watson, M.R. Tournament rituals in the evolution of fields: The case of the Grammy Awards. Acad. Manage. J. 2004, 47, 59-80.

24. Jungk, R.; Müllert, N. Zukunftswerkstätten. Wege zur Wiederbelebung der Demokratie; Hoffmann and Campe: Hamburg, Germany, 1981.

25. Troxler, P.; Kuhnt, B. Future workshops. The unthinkable and how to make it Happen. In Hands-On Knowledge Co-Creation and Sharing: Practical Methods and Techniques; Abdul, S.K., Liza, W., Patricia, W., Eds.; VTT: Helsinki, Finland, 2007; pp.483-495.

26. Owen, H. Open Space Technology: A User's Guide; Berrett-Koehler: San Francisco, CA, USA, 1997.

27. Shotter, J.; Gustavsen, B. The Role of 'Dialogue Conferences' in the Development of the 'Learning Regions': Doing 'from within' Our Lives Together What We Cannot Do Apart; The Centre for Advanced Studies in Leadership; Stockholm School of Economics: Stockholm, Sweden, 1999.

28. Ekman Philips, M.; Huzzard, T. Developmental magic? Two takes on a dialogue conference. $J$. Organ. Change Manage. 2007, 20, 8-25.

29. Jones, K. A biographic researcher in pursuit of an aesthetic: The use of arts-based (re)presentations in "performative" dissemination of life stories. Qual. Soc. Rev. 2006, 2, 66-85.

30. Guiney Yallop, J.; Lopez de Vallejo, I.; Wright, P. Editorial: Overview of the performative social science special issue. Qual. Soc. Rev. 2008, 9, Art. 64. Available online: http://www.qualitativeresearch.net/index.php/fqs/article/view/375/817 (accessed on 28 May 2009).

31. Roberts, B. Performative social science: A consideration of skills, purpose and context. Qual. Soc. Rev. 2008, 9, Art. 58. Available online: http://www.qualitative-research.net/index.php/fqs/article/ view/377/822 (accessed on 29 May 2009).

32. Luhmann, N. Social Systems; Stanford University Press: Stanford, CA, USA, 1995.

33. Gergen, K. The social constructivist movement in modern psychology. Amer. Psychol. 1985, 40, 266-275.

34. Mead, G.H. Mind, Self, and Society. From the Standpoint of a Social Behaviorist; University of Chicago Press: Chicago, IL, USA, 1972.

35. Carlile, P. A pragmatic view of knowledge and boundaries: Boundary objects in new product development. Organ. Sci. 2002, 13, 442-455.

36. Dewe, B. Von der Wissenstransferforschung zur Wissenstransformation: VermittlungsprozesseBedeutungsänderungen. In Wissenstransfer durch Sprache als gesellschaftliches Problem; Gerd, A., Sigurd, W., Eds.; Peter Lang Verlag: Frankfurt am Main, Germany, 2005; pp. 365-379.

37. Gergen, K.J.; Thatchenkerry, T.J. Organization science as social construction: Postmodern potentials. J. Appl. Behav. Sci. 1996, 32, 356-377.

38. Bandura, A. Social Foundations of Thought and Action: A Social Cognitive Theory; Prentice Hall: Englewood Cliffs, NJ, USA, 1986.

39. Richardson, G.R.A.; Lynes, J.K. Institutional motivations and barriers to the construction of green buildings on campus: A case study of the University of Waterloo, Ontario. Int. J. Sustain. Higher Educ. 2007, 8, 339-354. 
40. Barth, M.; Godemann, J.; Rieckmann, M.; Stoltenberg, U. How to develop key competencies for dealing with sustainable development in higher education. Int. J. Sustain. Higher Educ. 2007, 8, 416-430.

41. Karol, E. Using campus concerns about sustainability as an educational opportunity: A case study in architectural design. J. Clean. Prod. 2006, 14, 780-786.

42. Watson, T.J. Rhetoric, discourse and argument in organizational sensemaking: A reflexive tale. Organ. Stud. 1995, 16, 805-821.

43. Weick, K.E. Sensemaking in Organizations; Sage: London, UK, 1995.

44. Hansmann, R.; Mieg, H.A.; Scholz, R.W.; Crott, H.W. Shifting Students' to Experts' complex systems knowledge: Effects of bootstrapping, group discussion, and case study participation. Int. J. Sustain. Higher Educ. 2003, 4, 151-168.

45. Scholz, R.W.; Tietje, O. Embedded Case Study Methods: Integrating Quantitative and Qualitative Knowledge; Sage: Thousand Oaks, CA, USA, 2002.

46. Scholz, R.W.; Lang, D.J.; Wiek, A.; Walter, A.I.; Stauffacher, M. Transdisciplinary case studies as a means of sustainability learning: Historical framework and theory. Int. J. Sustain. Higher Educ. 2006, 7, 226-251.

47. Lewin, K. Group Decision and Social Change. In Readings in Social Psychology; Swanson, G.E., Newcomb, T.M., Hartley, E.L., Eds.; Holt: New York, NY, USA, 1952; pp. 459-473.

48. Werner, C.M. Changing homeowners' use of toxic household products: A transactional approach. J. Environ. Psychol. 2003, 23, 33-45.

49. Ajzen, I. The theory of planned behavior. Organ. Behav. Hum. Decision Proc. 1991, 50, 179-211.

50. Petty, R.E.; Cacioppo, J.T. Communication and Persuasion: Central and Peripheral Routes to Attitude Change; Springer: New York, NY, USA, 1986.

51. ETH Zurich/Corporate Communications. ETH Zurich Annual Report, ETH Zurich: Zurich, Switzerland, 2009.

52. ETH Life Print. Umweltziele Umsetzen: Nachtschicht für die Nachhaltigkeit; ETH Life Print: Zurich, Switzerland, 2008; Volume 12, p. 6.

53. Eisenhardt, K.M. Building theories from case study research. Acad. Manage. Rev. 1989, 14, 532-550.

54. Yin, R.K. Case Study Research. Design and Methods; Sage: Thousand Oaks, CA, USA, 2003.

55. Denzin, N. The Research Act: A Theoretical Introduction to Sociological Methods, 3rd ed.; Prentice Hall: Englewood Cliffs, NJ, USA, 1989.

56. Flick, U. Triangulation revisited: Strategy of validation or alternative? J. Theor. Soc. Behav. 1992, 22, 175-197.

57. Junker, B. Field Work; University of Chicago Press: Chicago, IL, USA, 1960.

58. Gold, R. Roles in sociological fieldwork. Soc. Forces 1958, 36, 217-223.

59. Hammersley, M.; Atkinson, P. Ethnography; Routledge: New York, NY, USA, 2007.

60. Holstein, J.A.; Gulbrium, J.F. Interpretative practice and social action. In Strategies of Qualitative Inquiry; Denzin, N.K., Lincoln, Y.S., Eds.; Sage: Thousand Oaks, CA, USA, 2008; pp. 173-203.

61. Flick, U. An Introduction to Qualitative Research, 4th ed.; Sage: London, UK, 2009. 
62. Schütze, F. Die Technik des narrativen Interviews in Interaktionsfeldstudien-dargestellt an einem Projekt zur Erforschung von kommunalen Machtstrukturen. Arbeitsberichte und Forschungsmaterialien Nr. 1; Universität Bielefeld, Fakultät für Soziologie: Bielefeld, Germany, 1977.

63. Bryman, A.; Bresnen, M.; Beardswoth, A.; Keil, T. Qualitative research and the study of leadership. Hum. Relat. 1988, 41, 13-30.

64. Miles, M.B.; Huberman, A.M. Qualitative Data Analysis. A Source Book of New Methods; Sage: Beverly Hills, CA, USA, 1994.

65. Prior, L. Using Documents in Social Research; Sage: London, UK, 2003.

66. Wehrli, F. Ökologische Verantwortung Wahrnehmen; ETH Life Print: Zurich, Switzerland, 2009; p. 13. Available online: http://www.ethz.ch/about/publications/life_print/2009/eth_life_ print_09_01.pdf (accessed on 23 January 2011).

67. ETH Zurich/Brem, D. Ecoworks-ETH Platform for Reduction of $\mathrm{CO}_{2}$ Emissions and Increased Energy Efficiency; ETH: Zurich, Switzerland, 2009. Available online: http://www.ecoworks.ch/ attachments/Ecoworks_Bericht_ENG_small.pdf (accessed on 28 May 2009).

68. Langhart, L. Beim Essen an die Umwelt Denken; ETH Life: Zurich, Switzerland, 25 November 2009. Available online: http://www.ethlife.ethz.ch/archive_articles/091125_eaternity_lul/index (accessed on 21 January 2011).

69. SupportMNM. From here to Eaternity... the meat-free project to calcualte the carbon cost of your food. 7 May 2010. Available online: http://www.supportmfm.org/news/from-here-to-eaternitythe-meat-free-project-to-calculate-the-carbon-cost-of-your-food.cfm (accessed on 23 January 2011).

70. Santoro, A.; Benkler, C.; Moes, L.; Art, S.; Roald, L. ASVZ-Energy Recovery-System (AERS). 2009. Available online: http://eco-works.ch/documents/Ecoworksprojekt.pdf (accessed on 23 January 2010).

71. Paulides, J.J.H.; Jansen, J.W.; Encica, L.; Lomonova, E.; Smit, M. Human-powered small-scale generation system for a sustainable dance club. In Proceedings of the Electric Machines and Drives Conference, IEMDC 2009, Miami, FL, USA, 3-6 May 2009; pp. 439-444.

72. Brunner, A.; Elmer, F. Implementing Sustainability in Conferences-Recommendations Applied to the Alliance for Global Sustainability Annual Meeting 2009, Zurich, Switzerland, June 2009. Available online: http://theags.org/wp-content/uploads/AGS2009_SustainableConference.pdf (accessed on 23 January 2011).

73. Jaquemet, D.F. Mit desem Fussabdruck lief die SOLA 2010! Ökobilanz einer Laufveranstaltung mit Schwerpunkt $\mathrm{CO}_{2}$ Bilanz; Institut für Ökologisches Systemdesign, ETH: Zürich, Switzerland, 2010. Available online: http://www.ecoworks.ethz.ch/projekte/documents/LCA-SOLA2010Dominique-Jaquemet.pdf (accessed on 23 January 2011).

74. Hansmann, R.; Mieg, H.A.; Frischknecht, P.M. Qualifications for contributing to sustainable development: A survey of Environmental Sciences graduates. GAIA 2010, 19, 278-286.

75. Hansmann, R.; Crott, H.W.; Mieg, H.A.; Scholz, R.W. Improving group processes in transdisciplinary case studies for sustainability learning. Int. J. Sustain. Higher Educ. 2009, 10, $33-42$. 
76. Stauffacher, M.; Walter, A.; Lang, D.; Wiek, A.; Scholz, R.W. Learning to research environmental problems from a functional social-cultural constructivism perspective: The transdisciplinary case study approach. Int. J. Sustain. Higher Educ. 2006, 7, 252-275.

(C) 2011 by the authors; licensee MDPI, Basel, Switzerland. This article is an open access article distributed under the terms and conditions of the Creative Commons Attribution license (http://creativecommons.org/licenses/by/3.0/). 